\title{
Differenz
}

Revista internacional de estudios heideggerianos y sus derivas contemporáneas

AÑO 3 NÚMERO 2: JULIO DE 2016. e-ISSN: 2386-4877 - DOI: 10.12795/DIFFERENZ.2016.I02.18

[pp. 273-277]

\section{HEIDEGGER, M. (2003): El concepto de Tiempo. Madrid. Trotta. 69 pp. Trad. Raúl Gabás Pallás y Jesús Adrián Escudero}

\author{
Julio Ramírez Jaramillo \\ Universidad de Sevilla (US)
}

El concepto de Tiempo (Der Begriff der Zeit) es una conferencia dada ante la sociedad Teológica de Marburgo, dictada por el mismo Heidegger, el 25 de julio de 1924. En ella se pueden apreciar algunos de los conceptos claves de la filosofía del autor, conceptos tales como la temporalidad del Dasein, el "ser en cada caso mío", así como el ser-temporalidad, algo característico del Dasein, este apropiamiento de la temporalidad de uno mismo. Estos conceptos son parte de las semillas que terminarán por germinar en Ser y Tiempo, entre ellos pueden verse, además, el reflejo de la importancia de la cotidianidad para el autor, cotidianidad en la cual se mueve el "uno".

Por otro lado se nota también la ausencia de algunas de las piezas claves en la filosofía de Martin Heidegger, conceptos tales como la angustia, la destrucción de la ontología (ontoteo-logia) mantenida hasta ahora y la necesidad de este abbau.

En primer lugar se trata la cuestión acerca del tiempo de una forma inmediata y propia de la cotidianidad, esto es, con un "qué" y a modo de pregunta. Se cosifica el mismo tiempo y se reduce a un "qué" al que podamos acceder, con el que podamos trabajar. Pero, claro está, para realizar un acceso al tiempo es necesaria una comprensión del sentido mismo de este, sentido que el tiempo encuentra en su eternidad. El lugar donde deberíamos colocarnos aquí es en el de la perplejidad, así sería para el filósofo, ya que el teólogo simplemente tendría que asumir la idea de que Dios es, así mismo, algo eterno 
y, por tanto, Dios es la temporalidad misma. Ante este razonamiento, dice Heidegger, la perplejidad es lo único que cabe, puesto que, de otro modo, asumir esto sería indicar que la temporalidad, al igual que la creencia en Dios, es un asunto de fe, por ello la Filosofía jamás podría acceder a la temporalidad en modo alguno.

La consideración del tiempo, entonces, tan sólo podría hacer más difícil la pregunta por la eternidad, su sentido sería plantearla y prepararla, dice Heidegger, en el recto modo y plantearla en el sentido más propio. Aunque esta reflexión, al no pretender buscar una determinación sistemática y universalmente válida, no sería algo propio de la Filosofía, al menos no de la que se ha hecho hasta ahora.

Se tratan las diversas consideraciones del tiempo, tanto las realizadas por el ámbito del negocio, esto es: de las ciencias, como las llevadas a cabo en el sentido más cotidiano.

Se asocia el tiempo, de modo cotidiano, a un reloj, el cual mide y cuantifica el tiempo en base a la repetición de un patrón de carácter cíclico, ajeno a toda posible alteración externa. Entonces el físico trabaja con estas mediciones, aquí ya entraría la faceta del negocio en el momento que aprovechamos este método de carácter cientificista con el fin de realizar cálculos, es entonces cuando trata de medir el tiempo, pero esta comprensión del tiempo no es más que algo meramente superficial, las mediciones indican el Cuánlargo (Wielange) y el Cuándo (Wann), con esto llegamos al Desde-cuándo-hasta-cuándo (Von-wann-bis-wann). Pero este modo de medir el tiempo no es más que la ya mencionada repetición cíclica de un mecanismo físico ajeno a toda alteración externa, la división de este tiempo es algo arbitrario, el reloj no es más que una secuencia. El reloj, pues, nos enseña que es posible fijar, de modo arbitrario, un punto-ahora en el tiempo, de modo que una vez son fijados dos puntos uno se sitúa como más temprano y el otro como más tarde, el tiempo es completamente homogéneo.

Entonces, una vez nos dirigimos al acontecimiento con el reloj y decimos: esto ocurre ahora. ¿Qué es el ahora? Heidegger nos plantea, no sólo qué es sino dónde reside este "ahora". ¿Reside en mí mismo? Es decir, ¿soy yo el ahora? ¿o son los otros existentes el ahora? Este planteamiento nos lleva, irremisiblemente, a la conclusión de que yo mismo soy el tiempo, los otros son también este tiempo y en nuestro estar-uno-con-otro seríamos, a la vez, todos, y ninguno, tiempo.

Vemos aquí reflejada la idea de la temporalidad del Dasein como parte constitutiva de su propia existencia, somos tiempo y estamos sujetos a una temporalidad que nos es propia, en nuestro desenvolvernos-con-los-demás compartimos una temporalidad, esta no es propia de nadie, sino que es ajena a todos, pero, al mismo tiempo, nos constituye y nos conforma. Al medir el tiempo, ya sea como un cálculo de un punto a otro, o como 
una demarcación del más-tarde/más-temprano, o, simplemente, como la fijación de un "ahora", es cuando el existente se encuentra a sí mismo. Cuando es el existente quien exclama un "iahora!" el Dasein (se) hace referencia a una temporalidad en la que está sumergido y no sólo sumergido, sostenido. Puesto que su vida no es nada sin esta temporalidad $y$, al tiempo, esta temporalidad precisa de la vida del existente para ser medida, vivida, como tal.

Enuncia, en esta conferencia, las características del Dasein en función de la temporalidad del mismo, vemos aquí las bases de algo que terminará de estar asentado en su obra Ser y Tiempo. Nombra así ocho características para definir al Dasein, entre ellas aparecen ideas tales como:

La idea del Dasein como ser-en-el-mundo, con su correspondiente estado de arrojado o eyecto hacia el mismo, la característica del ser-con-otros, esto es en las relaciones del existente con el resto de individuos, una relación del ser-uno-para-otros pero sin llegar a estar "a la mano" (Vorhandensein) como podría estarlo cualquier instrumento. También se manifiesta la idea del hablar como situación o momento en el que la existencia de uno se pone en juego, el modo en el que el Dasein se auto-comprende y comprende tanto a los otros como a su mundo, reside aquí la auto-interpretación del presente. La eventualidad del "yo soy" como algo constitutivo del existente y cómo este "yo soy", propio del Dasein, convive con el "nosotros" que reside en la convivencia con otros existentes, cómo nadie es él mismo en la cotidianidad, pasando entonces a ser el "Uno", el reflejo de todos los que conforman esta cotidianidad, cotidianidad en la cual no reside una reflexión del Dasein sobre el sí-mismo o el yo, sin embargo en esta cotidianidad el Dasein se tiene a sí mismo. Se encuentra consigo mismo en su trato cotidiano con las cosas, en su mundear. Aparece como última idea constitutiva del concepto de Dasein el hecho de que este mismo existente no puede señalarse, esto es, su relación primaria consigo mismo no reside en la contemplación, sino en el "serlo", el hablar-sobre-sí-mismo y la auto-interpretación forman parte de un determinado modo señalado en que el Dasein se tiene, en cada caso, a sí-mismo.

Una vez ha concluido esta reflexión sobre las características del Dasein no sólo queda definido el existente mismo, sino también queda definido el concepto del "Uno" y la cotidianidad que conforma la esfera de la tradición y lo ya-interpretado. Se ve, también, cómo el Dasein queda, en cierto modo, "anulado", en el sentido de ser-propio, cuando se deja llevar por la cotidianidad, por el "uno", esto es: por el ser-en-cada-caso-para-conotros. El Dasein no se cuestiona, no se pone en estado de perplejidad, en la cotidianidad donde normalmente se desenvuelve, en este estado de ser-para-con-todos el Dasein pierde el acceso a sí mismo pese a tenerse en cada caso. El Dasein no debe dejarse 
oscurecer por esta cotidianidad sino que debe buscar hacerse propio-en-cada-caso de un modo consciente.

Pero ¿cómo puede, entonces, conocerse este Dasein a sí mismo? ¿Cómo si está aún en camino a su "definición" final? Es decir, el Dasein no está constitutivamente formado hasta que abraza su finitud, hasta que muere, es entonces cuando se ve completado puesto que ya ha "padecido" todas las experiencias de su vida. En palabras del propio Heidegger: "Y cuando ha llegado a fin, ya, precisamente, no es más. Antes de este fin jamás es propiamente lo que puede ser; y si lo es, entonces ya no lo es más."

También surge la cuestión en la misma conferencia de si el Dasein de los otros podría sustituir al propio, esto queda zanjado con un rotundo no, debido a la intransferibilidad de la experiencia, no podemos "padecer" las vivencias del resto de existentes, por ende no podemos vivir su mismo fin, esto conduciría a la nada más absurda y absoluta. La eventualidad debe tenerse firmemente como mía, jamás puede tenerse el Dasein de otro en modo originario y tan sólo en modo originario es como uno puede tener (más bien ser) Dasein. "Yo nunca soy el otro."

No debemos escabullirnos de esta perplejidad, nos dice Heidegger, sino demorarnos en ella, ya que cuanto más estamos sumergidos en esta perplejidad más se nos esclarece y se deja ver la dificultad de aquello que le depara al Dasein, dificultad que se muestra en su posibilidad más extrema. El fin de mi Dasein, mi muerte, es mi posibilidad más extrema y absoluta, es aquí donde el Dasein tiene la oportunidad de encontrarse consigo mismo de la forma más absoluta, al encontrarse con su propia muerte se encuentra, a su vez, con la más extrema posibilidad de ser de él mismo. Esta extrema posibilidad del ser está marcada por una extrema certeza, la cual aparece cruzada, atravesada, por una enorme indeterminación articulada en base a un estar-por-delante, esto es, la indeterminada certeza de la más propia posibilidad del ser-hacia-el-fin. (Zu-Ende-seins).

En relación con el concepto del tiempo y esta finitud de la temporalidad humana Heidegger nos dice que el Dasein como vida humana es primariamente ser-posible, el ser de la posibilidad del haber-pasado cierto y, no obstante, indeterminado. El ser de la posibilidad es, siempre, la posibilidad, de modo que el ser sabe de su muerte, como interpretación del Dasein, este tiene a la mano el disimular de esta posibilidad de su ser.

En la proyección hacia el haber-pasado se produce un desbandamiento de todas las familiaridades, este haber-pasado no es un incidente en el Dasein, no es un "qué", sino un "cómo", este haber-pasado hacia el cual el Dasein puede precursar en cuanto que es mío es el cómo de mi Dasein. 
El precursar del Dasein no es otra cosa que el propio y único futuro del Dasein propio, en este ser-futuro el existente vuelve sobre su pasado y su presente propio. Cuando el Dasein es concebido en la más absoluta posibilidad de su ser deja de ser en el tiempo y pasa a ser el tiempo mismo. No tener tiempo es arrojar el tiempo en el mal presente de la cotidianidad, en cambio el ser-futuro no sólo da tiempo, sino que configura el presente y permite repetir el pasado en el cómo de su ser vivido.

Vemos entonces que el fenómeno fundamental del tiempo es el futuro, para ver esto el Dasein debe mantenerse en su precursar. Aquí se pone de manifiesto que el trato originario con el tiempo no es de ningún modo la medición. Es el ser-futuro, como posibilidad eventual del Dasein, aquello que da tiempo, ya que es el tiempo mismo. El tiempo no tiene, propiamente, tiempo para calcular el tiempo, la futuridad es aquello propiamente constitutivo del tiempo.

Preguntando acerca del tiempo, inquiriendo por el "cuándo" y el "cuánto" con el reloj en la mano, es así cómo el Dasein pierde el tiempo, es este Dasein, completamente inmerso en la contabilización del tiempo, en su medición, aquel que, precisamente, dice: no tengo tiempo. ¿No está aquí traicionándose a sí mismo en su uso del tiempo, en la medida en que él es tiempo? Pierde el tiempo y se provee, para ello de un reloj, algo, cuanto menos, irónico.

Para cerrar concluyamos esto como lo empezamos, por la pregunta por el "qué" es el tiempo. El tiempo no es el "qué", es el Cómo. Al inquirir uno sobre el tiempo no debe apegarse a una respuesta que siempre enuncia un "qué".

La pregunta se ha transformado, ya no es “¿Qué es el tiempo?”, sino “¿Quién es el tiempo?" podemos ceñirnos más y veremos que el tiempo no es un mero "quién", más bien veremos que cada-uno-en-cada-caso es el tiempo-propio. Al cuestionarnos por el tiempo demostramos que el Dasein mismo es cuestionable, ya que es este Dasein, encada-caso-propio, es el tiempo. 